\title{
Study on adult career planning on adult education program and assessment of adaptive design model
}

\author{
I-Chan Kao ${ }^{\mathrm{a}}$ \\ General Education Center, Open University of Kaohsiung, Taiwan
}

\begin{abstract}
This study explores adults' on-the-job current career planning and the selection trends of future development as the criteria for a training program design for adult education and the basis of the design model of adaptive assessment. This study regards the contents of the TTQS training process, the items, indicators, and standards of the Workforce Development Agency, and the occupational categories of the "Occupational Competency Standards", as disclosed by the "Integrated Competency and Application Platform", as the framework for the reference model; and probes into the impact of globalization, adult career planning, adult occupational training program design, and adaptive assessment, and adopts a questionnaire survey to understand the design model of the adaptive adult education program, in order to effectively implement adaptive assessment. The purposes are to assist adults to accomplish adaptive career planning, achieve their goals of vocational cultivation, and solve the problems of adult unemployment, in order to lead to successful adult employment and transfer to globalization workplaces to create positive career development.
\end{abstract}

\section{Introduction}

\subsection{Research motives}

Under the influence of global free markets and workplace environments, adult career planning and development are increasingly diverse and complex. Participating in competency development and enhancing learning activities is one of the ways to avoid becoming redundant in the face of constant changes in the market and workplace. Presently, Taiwan is confronted with globally competitive workplace environments, where expatriates, downsizing, layoffs, unpaid leaves, outsourcing and dispatch, reduced salaries and welfare, and other issues, have impact on workplace environments. In addition, the increased speed of technological development and the convenience of life and workplace operations have changed the operational trend of business organizations; for example, the "virtual office" refers to non-traditional offices that engage in work related to traditional offices[1].

Through literature review and questionnaire survey, this study examines the dramatic changes faced by adult learners in the workplace, particularly in the face of continuous changes in the global economic sector and the gradual complete replacement of laborers with a mechanical force for comprehensive automatic production, as caused by "Industry 4.0". In addition, global energy conservation and carbon reduction environmental protection policies encourage countries to

\footnotetext{
${ }^{a}$ Corresponding author : kic0929@ouk.edu.tw
}

(C) The Authors, published by EDP Sciences. This is an open access article distributed under the terms of the Creative Commons Attribution License 4.0 (http://creativecommons.org/licenses/by/4.0/). 
constantly develop green energy and photovoltaic technology. Fueled by different emerging industry development policies, the industry chain of traditional petrochemical energy production faces its most serious crisis since the first generation of the industrial revolution. Confronted with the aforesaid reshuffling and integration of the global industrial environment, how adult learners can effectively develop career planning and master the competencies required by contemporary workplaces is an important topic for all current in-service training programs and pre-service education, as well as the motive of this study.

\subsection{Research purposes}

Based on the above research motives, this study has the following research objectives:

1. To understand the connotations of adult career planning, adult competency training programs, and assessment adaptability.

2. To explore the overview of the cognitive differences of adults with different backgrounds in adult competency training programs and assessment adaptability.

3. To analyze the relationship between adult competency training programs and assessment adaptability.

4. To propose feasible strategies for adult competency training programs and assessment adaptability of adult career planning, as based on the research results.

\subsection{Research purposes}

This study first employs literature review to collect books, periodicals, magazines, journals, papers, and other important literature regarding adult career planning, adult education programs, and adaptive assessment, and then, analyses such literature in order to obtain the basic concepts of this study. Secondly, this study sorts and summarizes the relevant literature, reviews and recommendations of scholars and experts regarding the studies and practices of adult career planning and adult education programs, as well as their adaptive assessment. Then, this study edits the Questionnaire of the Overview of Adult Competency Training Programs and Assessment Adaptability, and uses this questionnaire survey to investigate adult students receiving in-service training at the Open University of Kaohsiung. Through collection and statistical analysis of the data collected from the questionnaire, this study aims to understand adults' perceptions and cognitions of the status of competency training programs and adaptive assessment. This questionnaire survey is conducted in both paper and online questionnaire forms.

\section{Connotations of adult career planning, adult competency training programs, and assessment adaptability}

\subsection{Probe into the orientation of adult career planning and related issues}

The impacts of globalization on adult learning and education include the elimination of individualization, the collapse of original communities, delocalization, the rise of post-colonialism, rampancy of cultural hegemony and symbolic violence, and the mechanism of the capital-based market [2-4]. The scope that refers to adult learners is relatively broad, including adult students, mature students, non-traditional students, and other adult learners studying in the education system, as well as adults who engage in self-directed learning, informal learning, and other self-learning. The differences of learning behaviors between adult learners and general traditional learners are primarily resulted from the effects of adult learners' physical, psychological, and social factors, as well as personal characteristics [5-8].

Randall (1987) maintained that when an organization's commitment was low, employees were likely to have low career development and low promotion, which may result in resignation or striving 
to cause organizational goals to fail. Moreover, along with other changes in the labor force, the female labor force joined the market, which contributed to changes in business management strategies and social policies; and business owners were only willing to provide more stable and reasonable working conditions to core staff. However, it was difficult for non-core staff to get promoted, and such employees may be outsourced or dispatched, thus, long-term staff were replaced by "temporary employees" [10]. When workplace environments change too fast, and people experience different needs, develop cross-professional and cross-organizational career development models, and gradually break away from the traditional career development of "maturity" towards "adaptability "[11], it indicates that employees must equip themselves with various capabilities and determine whether their careers have reached the goals established for this stage, in order to effectively respond to current career trends.

Prior to the $1980 \mathrm{~s}$, career orientation was dominated by "linear direction", meaning individuals were promoted in organizations based on the positions planned by the organizations, individuals did not have the sense of "self", and regarded the goals of the company as their goals. However, with the rise of new concepts, such as protean careers and boundary less careers, after the 1980s, changes in the global environment were increasingly dramatic and factors of uncertainty increased, contributing to the "nonlinear" development of career orientation [12-13]. The multiple career concept model, as proposed by Driver et al. (1994), divided career orientation into linear, expert, spiral, and transitory, thus, careers were no longer regarded as linear, and the new concept was that a career was recyclable, reversible, nonlinear, and multi-trajectory [15]. Contemporary adults are in an era of changeable global workplaces, and careers have become unpredictable, fragile, and multi-oriented, leading to more complex career planning [1].

\subsection{Discussion of the connotations of adult competency development and related topics}

Competency is derived from McClelland (1973), who replaced competence measurement with intelligence, and used it as a predictor of personal success. The connotations of competency encompass knowledge, skills, and feelings, and competence is measure by external behaviors. Additionally, competence can be subdivided into the abilities "acquired" by individuals, and means the acquisition of knowledge, feelings, skills, and "demonstrated" abilities, namely, the successful completion of certain tasks according to the actual behavioral performances [16]. Cheng et al. (2009) defined competency as "an ability to use knowledge, attitude, and skills to perform a task, as well as all behaviors, motives, and knowledge about the success or failure of work [17]. In other words, the scope and context of competency are broader than those of ability, and are primarily related to the high-performance conditions required by a particular role or work, including the basic ability of the lowest standard [18-20].

Competency models refer to the combination of knowledge, skills, abilities, and other characteristics (KSAOs) necessary for high performance at work [21]. In addition, competency can be classified into professional competency, core competency, and management competency. Professional competency referred to the duty abilities of employees engaged in specific works, which they must possess in order to achieve specific work objectives. Secondly, core competency was common competency, also known as "common core competency", and was the competency each member of an organization must possess. Thirdly, management competency meant the duty abilities assumed by management in an organization, which they must possess to implement each stage of management [22-28].

With reference to the data of different countries, Taiwan's Workforce Development Agency (2015) established a reference structure of occupation categories with 16 areas, including (1) natural resources, food, and agriculture; (2) manufacturing; (3) building construction; (4) marketing and sales; (5) logistics and transportation; (6) leisure and sightseeing tourism; (7) information technology; (8) finance and accounting; (9) science, technology, engineering, and mathematics; (10) government public affairs; (11) judiciary, laws, and public security; (13) health care; (14) personal and social 
services; (15) arts and audio and video communication; (16) business operation and management [29]. In addition, the Occupational Competency Standard (OCS) meant that, without the restriction of specific work tasks, but with the scope of a few occupational competency standard units, the descriptions of work scopes were sorted, work tasks were developed, and the universality and necessity of the connotations of competency, as required by industry, were demonstrated. Moreover, grades were classified based on the maturity of occupational performance, which was the basis for the degree of professional occupational performance [29]. The items, indicators, and standards of occupational competency standards and competency grading are considered as reference for human resources training and career development, as well as a reference standard for developing adult employment, entrepreneurship, occupational change, and other competencies.

\subsection{Discussion of the models of adult competence training programs, connotations of assessment adaptability, and related topics}

\subsubsection{Models of adult competence training programs}

The American Society for Training and Development placed emphasis on the ADDIE model for training development, which includes the five stages of analysis, design, development, implementation, and evaluation [30-31], and renders the program design structured and systematic. Taiwan's Workforce Development Agency incorporated ISO10015, European vocational education and training (VET), UK Investors in People (IIP), Australia's active vocational training policy, and the challenges of a globalized knowledge-based economy, as faced by Taiwan, and formulated the "Talent Quality Management System" suitable for Taiwan [32-35].

TTQS stresses the construction of a strategic human resource development system, and improves the system with the training quality cycle of Plan $\rightarrow$ Design $\rightarrow$ Do $\rightarrow$ Review $\rightarrow$ Outcome (PDDRO), which includes detailed indicators and specifications, and can be used as an Indicator reference for engaging in the human resources training of an organization. In particular, "Plan" refers to the relevance of training planning and business development objectives, as well as the operational ability of the training system. "Design" refers to the systematic design of the training programs (including the participation of stakeholders, the degree of meeting demands, the standards for selecting programs, and procurement standards and procedures). "Do" refers to the degree of training implementation and the systematization of training records and management. "Review" refers to the regular implementation of analysis, whole-process monitoring, and exception handling of training. "Outcome" refers to the level and completeness of the assessment of training results and continuous training improvements [36]. There are similarities in the framework and processes of ADDIE TTQS, and PDDRO, and ADDIE has become the competency training operating system generally adopted by Taiwan's public institutions and training institutions at present.

In response to the industrial trend of Industry 4.0, adult career planning and competency training should be planned, designed, and executed by strengthening training customization, operational intelligence, educational efficiency, program integration, and other directions [37]. Tsai and Hsu (2004) and Chen (2013) carried out analysis of training programs for adult learning fields, which was divided into planning the following four learning fields: (1) Learning field of business organizations for workplace participation, where adult learners developed adult learning programs for competency orientation through growth learning and adaptability, and by means of training; (2) Learning field of education and training organizations for independent development, where adult learners developed skill training programs for application orientation through growth learning and innovative learning, and by means of education and training; (3) School learning field of participation in recurrent education, where teaching programs were developed through growth learning and transformative learning, and by means of education; (4) Life learning field of residential communities participated by residential communities, where life development learning programs were developed through transformative learning and adaptive learning, and via informal and liberal arts-oriented learning community awareness and social actions. 
Dalziel, et al. (2016) proposed the concept map of learning design (see Figure 1), which held that, regarding the formulation of learning maps for adult learners' career planning and competence development, creating specific learning objectives and teaching methods that meet adults' learning experiences can be used as the challenge framework of the learning design concept, where the adult learners' learning feedback, learning test assessment, learning behavior analysis, learning effectiveness evaluation, and other learner responses, were the bases for developing learning instruments and resources. Subsequently, the image-based demonstration of guiding knowledge and technological learning concepts were developed, and the shared core concept of the learning design was regarded as the recycling benchmark for the operation of various teaching activities, such as "design and planning of teaching activities $\rightarrow$ implementation of teaching activities $\rightarrow$ reflection feedback and improvement $\rightarrow$ teaching professional competency development". Additionally, the operational recycling of teaching activities must apply a philosophical foundation of education, teaching theories, and teaching methods, as well as the characteristics and values of learning environments, learning activities, theme discussions, curriculum modules, learning plans, and other teaching structures and levels, as the principle and reference structure of teaching operations, in order to attain the objectives of teaching activity design.

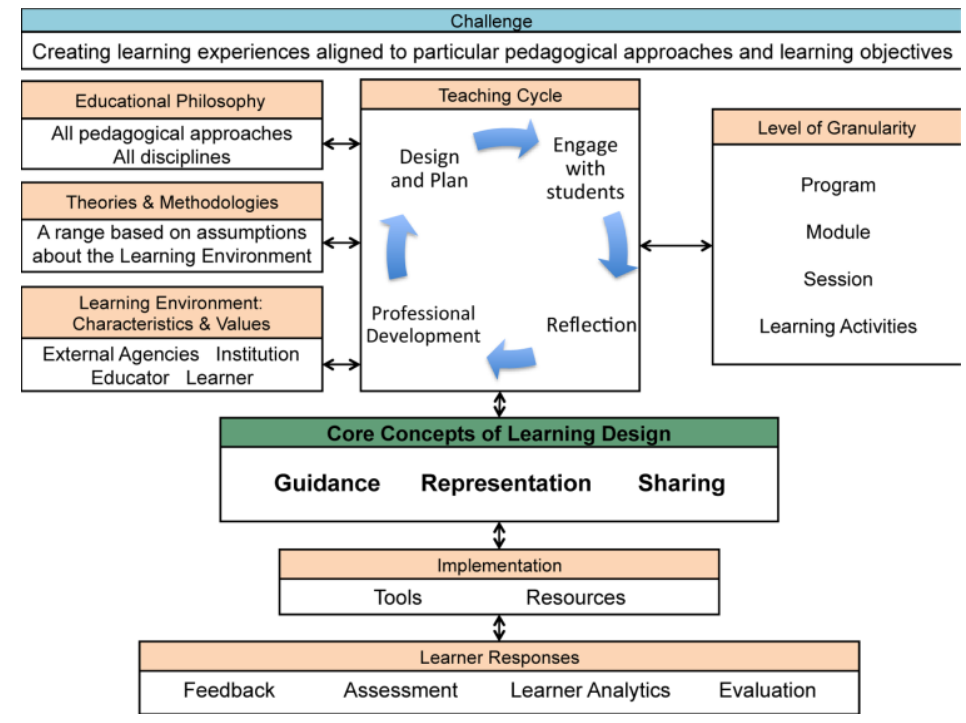

Figure 1. Concept Map of Learning Design. Source: Dalziel, et al., 2016, 10

\subsubsection{Assessment adaptability of adult competency training programs}

In addition to meeting the characteristics of adult learning, the adaptive assessment of adult competency training programs attaches greater importance to achieving the objectives of learning tasks and occupational performance as the specifications of learning effectiveness. The methods for collecting the results of assessment information regarding adult competency training include rigid information, such as output, time, cost, and quality, as well as soft data, such as work habits, skills, work atmosphere, pioneering initiative, and attitude. The six commonly used methods of information collection are, as follows: (1) Questionnaires: open, check, alternative, multiple choice questions, and rating; (2) Test: pen and paper tests - operation of examination, diagnosis, and preparation; oral tests work procedures, quality and speed of knowing how to do tasks, and doing them right and skillfully; (3) Interview: course response, learning effects, job application, and behavioral performance improvement; (4) Observation: multiple observations of many people from the assessment center; (5) Focus group: in-depth assessment information about training courses obtained from group discussions;

(6) Experimental design: one pre-test group and one post-test group [34]. 
The learning effectiveness of adult competency training programs include the following three major areas: (1) Cognition, meaning what trainees think they have learned from the training? Why they had to learn the content? How does the training help them and their work? (2) Affectivity, indicating whether the willing attitude of the trainees in training can cause resonance, and whether they can accept the training ways and contents? (3) Skill-based results, suggesting that trainees can systematically and gradually transfer what they have learned to their work to constantly strive for perfection; additionally, after their study contents serve the practical purposes, they must also understand whether their career planning and occupational performance have been improved, in order to demonstrate the final results of progress in personal and organizational performance after training, such as increased sales, increased production capacity, profit growth, reduced costs, improved quality, and decreased staff turnover rate. In addition, the cognition and feelings of high-level executives about the training developments in the organization are indispensable assessment items for the assessment system of performance-oriented training results, and the viewpoints of such high-level executives regarding training performance can be understood by regular questionnaire surveys and visits. Secondly, information about the internal operational performance of enterprises should be collected and analyzed in order to grasp the achievements of the business performances of different departments. Finally, the high-level executives refer to the executives that produced key influences on business objectives, strategies, and allocation of training resources [1].

The training result assessment, as proposed by Kirkpatrick (1998), involved reaction, learning, behavior and results, and the operation of TTQS and ADDIE training models and processes, which considered this assessment method as the main operational reference and basis. The adaptive assessment system of adult competency training programs could assess learning effectiveness in accordance with training procedures, and the content operation is, as follows [1], [39]:

1. Pre-training analysis: This assessment focuses on training needs and objectives, including whether the proposal, summarization, analysis, and identification of training needs are appropriate? Whether the analysis of the standards for achievable results through training is reasonable? Whether the selection of training objectives and participating employees is consistent with the business strategies of organizations?

2. Pre-training planning and development: This assessment concentrates on training program design, including whether the training plan is consistent with the business strategies of the organizations? Are the formulated training programs complete?

3. Implementation of training programs: This assessment focuses on the operation of training programs, including whether the program arrangements meet the training needs? Whether the training hours and time arrangements are appropriate? Whether the lecturers' expertise properly matches the training programs? Whether the training plan complies with the annual plan? In case of any differences, what are the reasons for such differences? What are the changes in the original planning and implementation? In case of any changes, what are the differences? Whether training funds and actual allocation are reasonable? Whether the written and oral tests are consistent with the teaching objectives?

4. Status of the objective achievements of trainees after training: This assessment concentrates on whether the trainees achieve their learning objectives, including the trainees' understanding of the theories and concepts in learning? Whether trainees grasp knowledge and skills in learning? How trainees improve their work attitudes and behaviors through learning?

5. Return to work of trainees after training: This assessment focuses on the application and effectiveness of training and learning, including how trainees' work attitudes and behaviors are improved after training? Whether the training helps trainees to improve their job performance? Whether the training helps trainees to hone their work abilities?

\section{Research hypotheses and tools}

\subsection{Research hypotheses}


This study integrates and summarizes the following hypotheses, as based on the discussions of the relevant topics of the abovementioned literature:

H1: Adults with different backgrounds have significant differences in their cognition and feelings regarding program design, program contents, and assessment adaptability.

$\mathrm{H} 2$ : Adults are significantly related to program design and contents.

H3: Adults have significant predictive power of the assessment adaptability of the program design

H4: Adults have significant predictive power of the assessment adaptability of the program contents.

\subsection{Research tools}

Through the abovementioned literature exploration and analysis, this study summarizes and edits the Preliminary Questionnaire about the Overview of Adult Competency Training Programs and Assessment Adaptability, and employs adult competency training practitioners, as well as scholars and experts of university research in adult education, as the experts of the expert validity of the questionnaires. With regard to adult competency training practitioners, one director from labor unions, chambers of commerce, and community development associations are invited, for a total of 3 practitioners. Secondly, in terms of university professors and scholars in charge of adult education or occupational training are invited, including seven experts, respectively, from National Pingtung University, National Pingtung University of Science and Technology, Lunghwa University of Science and Technology, National Kaohsiung First University, Aletheia University, National Open University, and Open University of Kaohsiung, who acted as the review experts for the expert validity of this study.

This study regards one class of adult learners receiving in-service training in counties and cities, as well as the Open University of Kaohsiung in Taiwan, as the sample unit, and employs a questionnaire survey of random sampling, in order to understand different personal background variables, such as gender, age, educational background, and occupation. The adult competency training program design includes five stratification factors: program needs, program planning, program development, program implementation, and program assessment, for a total of 25 questions. The program contents include three stratification factors: core competency, management competency, and professional competency, for a total of 25 questions. The assessment adaptability of learning effectiveness includes three stratification factors: learning satisfaction, improvement of knowledge-ability, and ensuring the study serves the practical purposes and competence performances, for a total of 20 questions. Through questionnaires, this empirical study regards the listed items as the hypotheses to verify this study, and the results as the operational system to improve future adult competency training programs and adaptive assessments, in order to enhance the benefits of adult competency training, improve occupational performance, and increase competitive advantages in the workplace.

\section{Research results}

\subsection{Descriptive statistical results}

The descriptive statistical results of this study are shown in Table 1. Regarding respondents' gender, there are 175 males, accounting for $52.1 \%$ of the total respondents, and 161 women, accounting for $47.9 \%$. In terms of the respondents' age, the number of "18-40 years old" is the largest, totaling 223 persons and accounting for $66.4 \%$ of the total number of respondents; 107 respondents are "41-60 years old", representing $31.8 \%$ of the total number of respondents, and 6 respondents are at least 61 years old, accounting for $1.8 \%$. Regarding the respondents' educational background, the number of respondents graduating from "senior high school and vocational school" is 147, accounting for 43.8\% of the total number of respondents; a total of 146 respondents graduated from "college and university", 
accounting for $43.5 \%$, and a total of 26 respondents from "graduate school" account for $7.7 \%$ of the total number of respondents. The least number of respondents graduated from "below (including) junior high school" account for only $5.1 \%$ of the total number of respondents. With regard to the occupational distribution of respondents, 188 respondents work in "information technology", accounting for $56.0 \%$ of the total number of respondents, and the least number of respondents in "farming, forestry, and fishing animal husbandry total 7 people, accounting for only $2.1 \%$ of the total number of respondents.

Table 1. Questionnaire about Program Design Models, Contents, and Competence Performance of Adult Competency Training.

\begin{tabular}{|c|c|c|c|c|}
\hline \multirow{2}{*}{ Variable } & Group & $\begin{array}{c}\text { Number of } \\
\text { people }\end{array}$ & Percentage & $\begin{array}{c}\text { Cumulative } \\
\text { Percentage }\end{array}$ \\
\hline \multirow{3}{*}{ Gender } & Male & 175 & 52.1 & 52.1 \\
\cline { 2 - 5 } & Female & 161 & 47.9 & 100.0 \\
\hline \multirow{4}{*}{ Age } & $18-40$ years old & 223 & 66.4 & 66.4 \\
\cline { 2 - 5 } & $41-60$ years old & 107 & 31.8 & 98.2 \\
\cline { 2 - 5 } & Above 61 years old & 6 & 1.8 & 100.0 \\
\hline \multirow{4}{*}{$\begin{array}{c}\text { Educational } \\
\text { background }\end{array}$} & Below (including) junior high school & 17 & 5.1 & 5.1 \\
\cline { 2 - 5 } & Senior high school and vocational & 147 & 43.8 & 48.8 \\
\cline { 2 - 5 } & school & 146 & 43.5 & 92.3 \\
\cline { 2 - 5 } & College and university & 26 & 7.7 & 100.0 \\
\hline \multirow{4}{*}{ Occupation } & Graduate school & 7 & 2.1 & 2.1 \\
\cline { 2 - 5 } & Farming, forestry, fishing animal & 12 & 3.6 & 5.7 \\
\cline { 2 - 5 } & husbandry & 92 & 27.4 & 33.0 \\
\cline { 2 - 5 } & Manufacturing & 188 & 56.0 & 89.0 \\
\cline { 2 - 5 } & Business and service & 27 & 8.0 & 97.0 \\
\cline { 2 - 5 } & Information technology & 10 & 3.0 & 100.0 \\
\hline
\end{tabular}

$\mathrm{N}=336$

\subsection{Confirmatory factor analysis of questionnaires}

\subsubsection{Validation of convergent validity}

Confirmatory factor analysis (CFA) is part of SEM analysis. Thomopson (2004) pointed out that this measurement model could correctly reflect the dimensions of a study, thus, analysis of the measurement model must be carried out prior to analysis of the SEM model. This study conducts SEM model testing according to the two-stage model analysis method proposed by Kline (2005). First, the measurement model is tested to determine whether the results show that the goodness of fit indicator of the measurement model is acceptable, then, assessment of the overall SEM model is carried out [50]. The CFA measurement indicators adopt the standards recommended by Hair, Anderson, Tatham, and Black (2009) and Fornell and Larcker (1981), as follows: (1) Factor loading is greater than .50; (2) Composite reliability is greater than .60; (3) the average extraction number of variables is greater than .50 . The CFA analysis results of this study illustrate that the factor loadings of the dimensions range between .71 to .94 , the composite reliability is from .91 to .97 , and the average extraction number of variables ranges from .68 to .84 (Table 2), indicating that the dimensions of this study have convergent validity. 
Table 2. Summary of Verification Information about Convergent Validity.

\begin{tabular}{|c|c|c|c|c|c|c|c|c|c|}
\hline \multicolumn{6}{|c|}{ Model Parameter Estimates } & \multicolumn{4}{|c|}{ Convergent Validity } \\
\hline $\begin{array}{c}\text { Latent } \\
\text { variables }\end{array}$ & $\begin{array}{c}\text { Observation } \\
\text { variables }\end{array}$ & $\begin{array}{c}\text { Non- } \\
\text { standardized } \\
\text { factor load }\end{array}$ & $\begin{array}{l}\text { Standard } \\
\text { error } \\
\text { S.E. }\end{array}$ & $\begin{array}{c}\mathrm{t}- \\
\text { value }\end{array}$ & $\mathrm{P}$ & $\begin{array}{c}\text { Standardized } \\
\text { factor load }\end{array}$ & SMC & C.R & AVE \\
\hline \multirow{5}{*}{ Program needs } & $\mathrm{Aa} 01$ & 1 & & & & 0.88 & 0.78 & \multirow{5}{*}{0.93} & \multirow{5}{*}{0.72} \\
\hline & $\mathrm{Aa} 02$ & 1.06 & 0.04 & 24.90 & $* * *$ & 0.92 & 0.84 & & \\
\hline & $\mathrm{Aa} 03$ & 0.98 & 0.04 & 22.93 & $* * *$ & 0.88 & 0.78 & & \\
\hline & $\mathrm{Aa} 04$ & 0.95 & 0.05 & 20.81 & $* * *$ & 0.84 & 0.71 & & \\
\hline & $\mathrm{Aa} 05$ & 0.87 & 0.06 & 15.56 & $* * *$ & 0.71 & 0.50 & & \\
\hline \multirow{5}{*}{$\begin{array}{l}\text { Program } \\
\text { planning }\end{array}$} & $\mathrm{Ab} 01$ & 1 & & & & 0.82 & 0.67 & \multirow{5}{*}{0.94} & \multirow{5}{*}{0.77} \\
\hline & $\mathrm{Ab} 02$ & 1.12 & 0.05 & 20.84 & $* * *$ & 0.90 & 0.82 & & \\
\hline & $\mathrm{Ab} 03$ & 1.10 & 0.06 & 19.23 & $* * *$ & 0.86 & 0.74 & & \\
\hline & $\mathrm{Ab} 04$ & 1.08 & 0.05 & 20.11 & $* * *$ & 0.88 & 0.78 & & \\
\hline & $\mathrm{Ab} 05$ & 1.15 & 0.06 & 20.83 & $* * *$ & 0.90 & 0.82 & & \\
\hline \multirow{5}{*}{$\begin{array}{c}\text { Program } \\
\text { development }\end{array}$} & $\mathrm{Ac} 01$ & 1 & & & & 0.89 & 0.80 & \multirow{5}{*}{0.95} & \multirow{5}{*}{0.79} \\
\hline & Ac02 & 1.02 & 0.04 & 25.51 & $* * *$ & 0.91 & 0.82 & & \\
\hline & $\mathrm{Ac} 03$ & 0.95 & 0.04 & 24.00 & $* * *$ & 0.88 & 0.78 & & \\
\hline & $\mathrm{Ac04}$ & 1.00 & 0.04 & 24.21 & $* * *$ & 0.89 & 0.79 & & \\
\hline & Ac05 & 0.92 & 0.04 & 22.73 & $* * *$ & 0.86 & 0.74 & & \\
\hline \multirow{5}{*}{$\begin{array}{c}\text { Program } \\
\text { implementation }\end{array}$} & Ad01 & 1 & & & & 0.94 & 0.88 & \multirow{5}{*}{0.96} & \multirow{5}{*}{0.84} \\
\hline & Ad02 & 0.99 & 0.03 & 32.37 & $* * *$ & 0.93 & 0.86 & & \\
\hline & $\mathrm{Ad} 03$ & 0.94 & 0.03 & 30.58 & $* * *$ & 0.91 & 0.83 & & \\
\hline & Ad04 & 0.99 & 0.04 & 27.23 & $* * *$ & 0.88 & 0.77 & & \\
\hline & Ad05 & 0.97 & 0.03 & 30.35 & $* * *$ & 0.91 & 0.83 & & \\
\hline \multirow{5}{*}{$\begin{array}{c}\text { program } \\
\text { assessment }\end{array}$} & $\mathrm{Ae} 01$ & 1 & & & & 0.87 & 0.76 & \multirow{5}{*}{0.94} & \multirow{5}{*}{0.76} \\
\hline & $\mathrm{Ae} 02$ & 1.02 & 0.04 & 23.73 & $* * *$ & 0.90 & 0.82 & & \\
\hline & $\mathrm{Ae} 03$ & 1.05 & 0.06 & 19.15 & $* * *$ & 0.81 & 0.65 & & \\
\hline & $\mathrm{Ae} 04$ & 0.95 & 0.04 & 21.80 & $* * *$ & 0.87 & 0.75 & & \\
\hline & $\mathrm{Ae} 05$ & 1.09 & 0.05 & 23.80 & $* * *$ & 0.91 & 0.82 & & \\
\hline \multirow{9}{*}{$\begin{array}{c}\text { Core } \\
\text { competency }\end{array}$} & $\mathrm{Ba} 01$ & 1 & & & & 0.84 & 0.71 & \multirow{9}{*}{0.97} & \multirow{9}{*}{0.77} \\
\hline & $\mathrm{Ba} 02$ & 1.03 & 0.05 & 20.86 & $* * *$ & 0.87 & 0.75 & & \\
\hline & $\mathrm{Ba} 03$ & 0.96 & 0.05 & 20.44 & $* * *$ & 0.86 & 0.73 & & \\
\hline & $\mathrm{Ba} 04$ & 1.01 & 0.05 & 20.81 & $* * *$ & 0.87 & 0.75 & & \\
\hline & $\mathrm{Ba} 05$ & 1.14 & 0.05 & 22.74 & $* * *$ & 0.91 & 0.83 & & \\
\hline & $\mathrm{Ba} 06$ & 1.09 & 0.05 & 21.58 & $* * *$ & 0.88 & 0.78 & & \\
\hline & $\mathrm{Ba} 07$ & 1.05 & 0.05 & 21.09 & $* * *$ & 0.87 & 0.76 & & \\
\hline & $\mathrm{Ba} 08$ & 1.10 & 0.05 & 22.32 & $* * *$ & 0.90 & 0.81 & & \\
\hline & $\mathrm{Ba} 09$ & 1.05 & 0.05 & 21.88 & $* * *$ & 0.89 & 0.79 & & \\
\hline \multirow{7}{*}{$\begin{array}{l}\text { Management } \\
\text { competency }\end{array}$} & $\mathrm{Bb} 01$ & 1 & & & & 0.82 & 0.67 & \multirow{7}{*}{0.97} & \multirow{7}{*}{0.79} \\
\hline & $\mathrm{Bb} 02$ & 1.16 & 0.06 & 20.38 & $* * *$ & 0.88 & 0.78 & & \\
\hline & $\mathrm{Bb03}$ & 1.11 & 0.05 & 21.21 & $* * *$ & 0.90 & 0.82 & & \\
\hline & $\mathrm{Bb} 04$ & 1.09 & 0.05 & 20.19 & $* * *$ & 0.88 & 0.77 & & \\
\hline & Bb05 & 1.16 & 0.06 & 20.92 & $* * *$ & 0.90 & 0.80 & & \\
\hline & $\mathrm{Bb06}$ & 1.19 & 0.05 & 22.08 & $* * *$ & 0.92 & 0.85 & & \\
\hline & $\mathrm{Bb} 07$ & 1.13 & 0.05 & 20.95 & $* * *$ & 0.90 & 0.80 & & \\
\hline
\end{tabular}




\begin{tabular}{|c|c|c|c|c|c|c|c|c|c|}
\hline \multicolumn{6}{|c|}{ Model Parameter Estimates } & \multicolumn{4}{|c|}{ Convergent Validity } \\
\hline \multirow[t]{3}{*}{$\begin{array}{c}\text { Latent } \\
\text { variables }\end{array}$} & $\begin{array}{c}\text { Observation } \\
\text { variables }\end{array}$ & $\begin{array}{c}\text { Non- } \\
\text { standardized } \\
\text { factor load }\end{array}$ & $\begin{array}{l}\text { Standard } \\
\text { error } \\
\text { S.E. }\end{array}$ & $\begin{array}{c}\mathrm{t}- \\
\text { value }\end{array}$ & $\mathrm{P}$ & $\begin{array}{l}\text { Standardized } \\
\text { factor load }\end{array}$ & SMC & C.R & AVE \\
\hline & $\mathrm{Bb} 08$ & 1.12 & 0.06 & 20.43 & $* * *$ & 0.88 & 0.78 & & \\
\hline & $\mathrm{Bb} 09$ & 1.13 & 0.05 & 21.25 & $* * *$ & 0.90 & 0.82 & & \\
\hline \multirow{6}{*}{$\begin{array}{l}\text { Professional } \\
\text { competency }\end{array}$} & $\mathrm{Bc} 01$ & 1 & & & & 0.83 & 0.69 & \multirow{6}{*}{0.96} & \multirow{6}{*}{0.79} \\
\hline & $\mathrm{Bc} 02$ & 1.10 & 0.05 & 22.07 & $* * *$ & 0.91 & 0.83 & & \\
\hline & $\mathrm{Bc} 03$ & 1.07 & 0.05 & 21.59 & $* * *$ & 0.90 & 0.81 & & \\
\hline & $\mathrm{Bc} 04$ & 1.13 & 0.05 & 21.72 & $* * *$ & 0.91 & 0.82 & & \\
\hline & $\mathrm{Bc} 05$ & 1.05 & 0.05 & 20.67 & $* * *$ & 0.88 & 0.77 & & \\
\hline & $\mathrm{Bc} 06$ & 1.07 & 0.05 & 21.04 & $* * *$ & 0.89 & 0.79 & & \\
\hline \multirow{5}{*}{$\begin{array}{l}\text { Learning } \\
\text { satisfaction }\end{array}$} & $\mathrm{Ca} 01$ & 1 & & & & 0.81 & 0.66 & \multirow{5}{*}{0.95} & \multirow{5}{*}{0.79} \\
\hline & $\mathrm{Ca} 02$ & 1.09 & 0.05 & 20.03 & $* * *$ & 0.89 & 0.79 & & \\
\hline & $\mathrm{Ca} 03$ & 1.14 & 0.05 & 21.81 & $* * *$ & 0.94 & 0.89 & & \\
\hline & $\mathrm{Ca} 04$ & 1.07 & 0.06 & 19.49 & $* * *$ & 0.88 & 0.77 & & \\
\hline & $\mathrm{Ca} 05$ & 1.07 & 0.05 & 20.60 & $* * *$ & 0.91 & 0.8273 & & \\
\hline \multirow{5}{*}{$\begin{array}{c}\text { Improvement } \\
\text { of knowledge- } \\
\text { ability }\end{array}$} & $\mathrm{Cb} 01$ & 1 & & & & 0.82 & 0.67 & \multirow{5}{*}{0.91} & \multirow{5}{*}{0.68} \\
\hline & $\mathrm{Cb02}$ & 1.18 & 0.06 & 20.26 & $* * *$ & 0.90 & 0.81 & & \\
\hline & $\mathrm{Cb} 03$ & 1.27 & 0.06 & 21.17 & $* * *$ & 0.93 & 0.86 & & \\
\hline & $\mathrm{Cb} 04$ & 0.53 & 0.05 & 11.42 & *** & 0.59 & 0.35 & & \\
\hline & $\mathrm{Cb} 05$ & 1.10 & 0.06 & 18.40 & $* * *$ & 0.84 & 0.71 & & \\
\hline \multirow{5}{*}{$\begin{array}{l}\text { Making study } \\
\text { serve the } \\
\text { practical } \\
\text { purpose }\end{array}$} & $\mathrm{Cc} 01$ & 1 & & & & 0.84 & 0.71 & \multirow{5}{*}{0.95} & \multirow{5}{*}{0.81} \\
\hline & $\mathrm{Cc} 02$ & 1.14 & 0.05 & 22.36 & $* * *$ & 0.90 & 0.82 & & \\
\hline & $\mathrm{Cc} 03$ & 1.21 & 0.05 & 22.69 & $* * *$ & 0.91 & 0.83 & & \\
\hline & $\mathrm{Cc} 04$ & 1.17 & 0.05 & 22.64 & $* * *$ & 0.91 & 0.87 & & \\
\hline & $\mathrm{Cc} 05$ & 1.19 & 0.05 & 23.02 & $* * *$ & 0.92 & 0.84 & & \\
\hline \multirow{5}{*}{$\begin{array}{l}\text { Competence } \\
\text { performance }\end{array}$} & $\mathrm{Cd} 01$ & 1 & & & & 0.84 & 0.71 & \multirow{5}{*}{0.94} & \multirow{5}{*}{0.75} \\
\hline & $\mathrm{Cd} 02$ & 1.09 & 0.05 & 21.80 & $* * *$ & 0.90 & 0.81 & & \\
\hline & $\mathrm{Cd} 03$ & 1.26 & 0.06 & 20.08 & $* * *$ & 0.86 & 0.73 & & \\
\hline & $\mathrm{Cd} 04$ & 1.11 & 0.06 & 18.48 & $* * *$ & 0.82 & 0.66 & & \\
\hline & $\mathrm{Cd} 05$ & 1.17 & 0.05 & 23.01 & $* * *$ & 0.93 & 0.86 & & \\
\hline
\end{tabular}

\subsubsection{Validation of discriminant validity}

Table 3. Bootstrap Correlation Coefficient in $95 \%$ Confidence Interval.

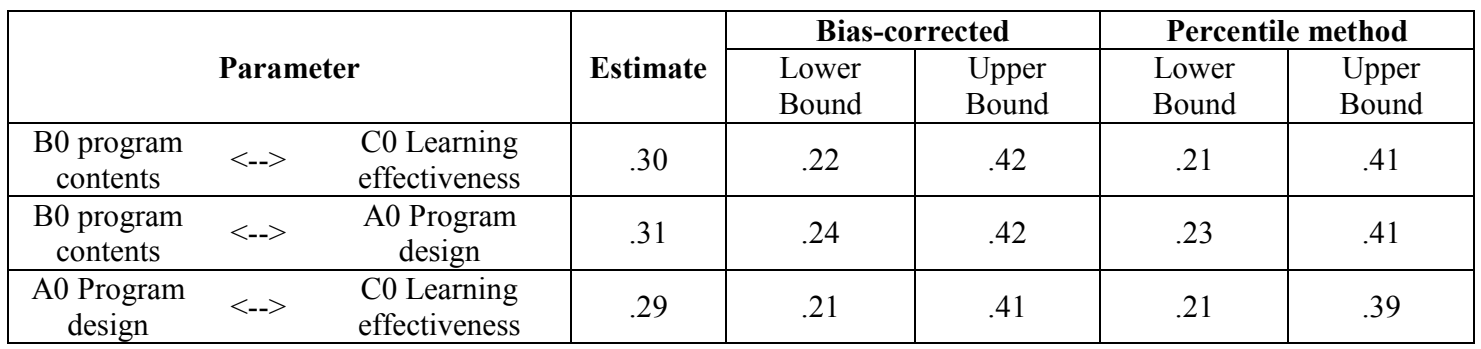

There are two estimates for the AMOS confidence interval: the Bias-corrected Percentile Method and

Percentile Method [49]. In this study, the bootstrap confidence interval is used to validate the 
discriminant validity of the dimensions, and the 1000 repetitions are estimated under the $95 \%$ confidence interval. If the correlation coefficient of dimensions is less than 1 in the $95 \%$ confidence interval, then the dimensions have discriminant validity [47], [49], [58]. The results of this study are presented in Table 3, and the confidence interval between dimensions is less than 1, showing discriminant validity in the three dimensions.

\subsubsection{Goodness of fit analysis}

In this study, the goodness of fit is based on the recommendations of Wu (2007), Hsu (2010), Bagozzi and Yi (1988), and Hair et al. (1998), verified with $\mathrm{p}^{2}$, and includes the ratio of $\mathrm{o}^{2}$ to degree of freedom, goodness of fit (GFI), adjusted goodness of fit (AGFI), root mean square error of approximation (RMSEA), comparative fit index (CFI), incremental fit index (IFI), and non-normed fit index (NNFI). However, when the sample size of SEM exceeds 200 , the chi-square value $\left(\chi^{2}=(n-1)\right.$ Fmin) is easily too large. In other words, a greater sample size results in a greater chi-square value, thus, the p value is easily refused [48-49]. hence, Bollen and Stine (1992) suggested using Bootstrap for model correction. As the chi-square value becomes smaller after correction, all GFIs must be recalculated, and the calculation results are shown in Table 4, which suggest that the GFI of the model meets the standards for judgment.

Table 4. Summary of GFI of the Model.

\begin{tabular}{|c|c|c|c|}
\hline Fitness Indicator & \multicolumn{2}{|c|}{ Standard Value } & Model GFI Judgment \\
\hline$\chi^{2}$ & The smaller the better & 4652.78 & Passed \\
\hline$\chi^{2} / \mathrm{df}$ & $<3$ & 2.06 & Passed \\
\hline GFI & $>.9$ & .87 & Accepted \\
\hline AGFI & $>.9$ & .86 & Accepted \\
\hline RMSEA & $<.08$ & .06 & Passed \\
\hline TLI (NNFI) & $>.9$ & .92 & Passed \\
\hline CFI & $>.9$ & .93 & Passed \\
\hline
\end{tabular}

\subsection{Analysis of the differences of different personal background variables in adult competency training programs and assessment adaptability}

The purpose of independent sample t testing is to infer whether the average value of the original two populations have statistical methods with significant differences after the average value of the two independent groups of samples are calculated [51]. In this study, the differences of different genders in the variables of the adult competency training program models are analyzed by independent samples t-testing. One-way ANOVA is used to test a single variable under different influences, and observe whether the average values of the variables have significant differences. If the test results show that the $\mathrm{F}$ value reaches significant level, it means that there is significant difference in at least one set of averages between the groups, and that "multiple-comparison post-hoc" analysis must be used to confirm the differences [45].

\subsubsection{Analysis of the differences of gender in adult competency training programs and assessment adaptability}

The gender differences of the research subjects in program design, program contents, and assessment adaptability are compared and analyzed. In accordance with the independent samples t-test results, gender difference shows no significant differences regarding the averages of program needs $(\mathrm{t}=-1.19$, $\mathrm{p}=.85)$, program planning $(\mathrm{t}=1.02, \mathrm{p}=.31)$, program development $(\mathrm{t}=-1.41, \mathrm{p}=.16)$, program implementation $(\mathrm{t}=.72, \mathrm{p}=.47)$, program assessment $(\mathrm{t}=-1.44, \mathrm{p}=.15)$, core competency $(\mathrm{t}=1.62, \mathrm{p}=.11)$, management competency $(\mathrm{t}=-1.50, \mathrm{p}=.13)$, professional competency $(\mathrm{t}=1.18, \mathrm{p}=.24)$, learning satisfaction $(\mathrm{t}=-1.35, \mathrm{p}=.18)$, improvement of knowledge-ability $(\mathrm{t}=1.12, \mathrm{p}=.26)$, ensuring study serves 
the practical purpose $(\mathrm{t}=-1.45, \mathrm{p}=.15)$, or competence performance $(\mathrm{t}=.78, \mathrm{p}=.44)$. In other words, different genders show no significant differences in adult competency training programs, program contents, or assessment adaptability.

\subsubsection{Analysis of the differences of age in adult competency training programs and assessment adaptability}

The age differences of the research subjects in program design, program contents, and assessment adaptability are compared and analyzed. According to the one-way ANOVA verification results, age difference shows no significant differences in the averages of program needs $(\mathrm{F}=2.40, \mathrm{p}=.09)$, program implementation $(\mathrm{F}=1.13, p=.33)$, program assessment $(\mathrm{F}=1.41, p=.25)$, core competency $(\mathrm{F}$ $=1.99, p=.14)$, management competency $(\mathrm{F}=-2.28, p=.10)$, professional competency $(\mathrm{F}=2.53, p=.08)$, learning satisfaction $(\mathrm{F}=-1.87, p=.16)$, improvement of knowledge-ability $(\mathrm{F}=1.77, p=17)$, ensuring study serves the practical purpose $(\mathrm{F}=-1.83, p=.16)$, or competence performance $(\mathrm{F}=1.76, p=.17)$. In other words, different ages show no significant differences in adult competency training programs, program contents, or assessment adaptability. However, program development $\left(\mathrm{F}=3.19^{*}, p=.04\right)$ reaches significant difference, and after Scheffe post-hoc comparison, all ages fail to reach significant differences.

\subsubsection{Analysis of the differences of educational background in adult competency training programs and assessment adaptability}

The educational background differences of the research subjects in program design, program contents, and assessment adaptability are compared and analyzed. According to the one-way ANOVA verification results, educational background difference shows no significant differences in the averages of program development $(\mathrm{F}=2.62, p=.05)$, program implementation $(\mathrm{F}=1.09, p=.35)$, or professional competency $(\mathrm{F}=1.97, p=.12)$. In other words, different educational backgrounds show no significant differences in adult competency training programs, program contents, or assessment adaptability. However, program demand $\left(\mathrm{F}=3.03^{*}, p=.03\right)$, core competency $\left(\mathrm{F}=3.24^{*}, p=.02\right)$, learning satisfaction $\left(\mathrm{F}=4.00^{*}, p=.01\right)$, and improvement of knowledge-ability $\left(\mathrm{F}=4.48^{*}, p=.00\right)$ reach significant differences. After Scheffe post-hoc comparison, the results show the differences of "graduate school" are greater than those of "college and university"; "ensuring study serves the practical purpose $\left(\mathrm{F}=5.86^{*}, p=.00\right)$, and competence performance $\left(\mathrm{F}=6.90^{*}, p=.00\right)$ reach significant differences. After Scheffe post-hoc comparison, the results show the differences of "graduate school" are greater than those of "senior high school and vocational school" and "college and university"; however, the differences of "senior high school and vocational school" and "college and university" fail to reach significant difference. Program planning $\left(\mathrm{F}=2.96^{*}, p=.03\right)$ and management competency $\left(\mathrm{F}=-2.94^{*}, p=.03\right)$ reach significant difference, and after Scheffe post-hoc comparison, no educational backgrounds reach significant differences.

\subsubsection{Analysis of the occupation differences in adult competency training programs and assessment adaptability}

The occupation differences of the research subjects in program design, program contents, and assessment adaptability are compared and analyzed. According to the one-way ANOVA verification results, the age difference shows no significant differences in the averages of program needs $(\mathrm{F}=.87$, $p=.50)$, program planning $(\mathrm{F}=.42, p=.84)$, program development $(\mathrm{F}=1.10, p=.36)$, program implementation $(\mathrm{F}=.72, p=.61)$, program assessment $(\mathrm{F}=.82, p=.53)$, core competency $(\mathrm{F}=.91, p=.47)$, management competency $(\mathrm{F}=.91, \mathrm{p}=.43)$, professional competency $(\mathrm{F}=.99, p=.42)$, learning satisfaction $(\mathrm{F}=1.84, p=.11)$, knowledge-ability $(\mathrm{F}=1.33, p=.25)$, ensuring study serves the practical purpose $(\mathrm{F}=1.05, p=.39)$, or competence performance $(\mathrm{F}=1.16, p=.33)$. In other words, different 
occupations show no significant differences in adult competency training programs, program contents, or assessment adaptability.

\subsection{Verification of study hypotheses}

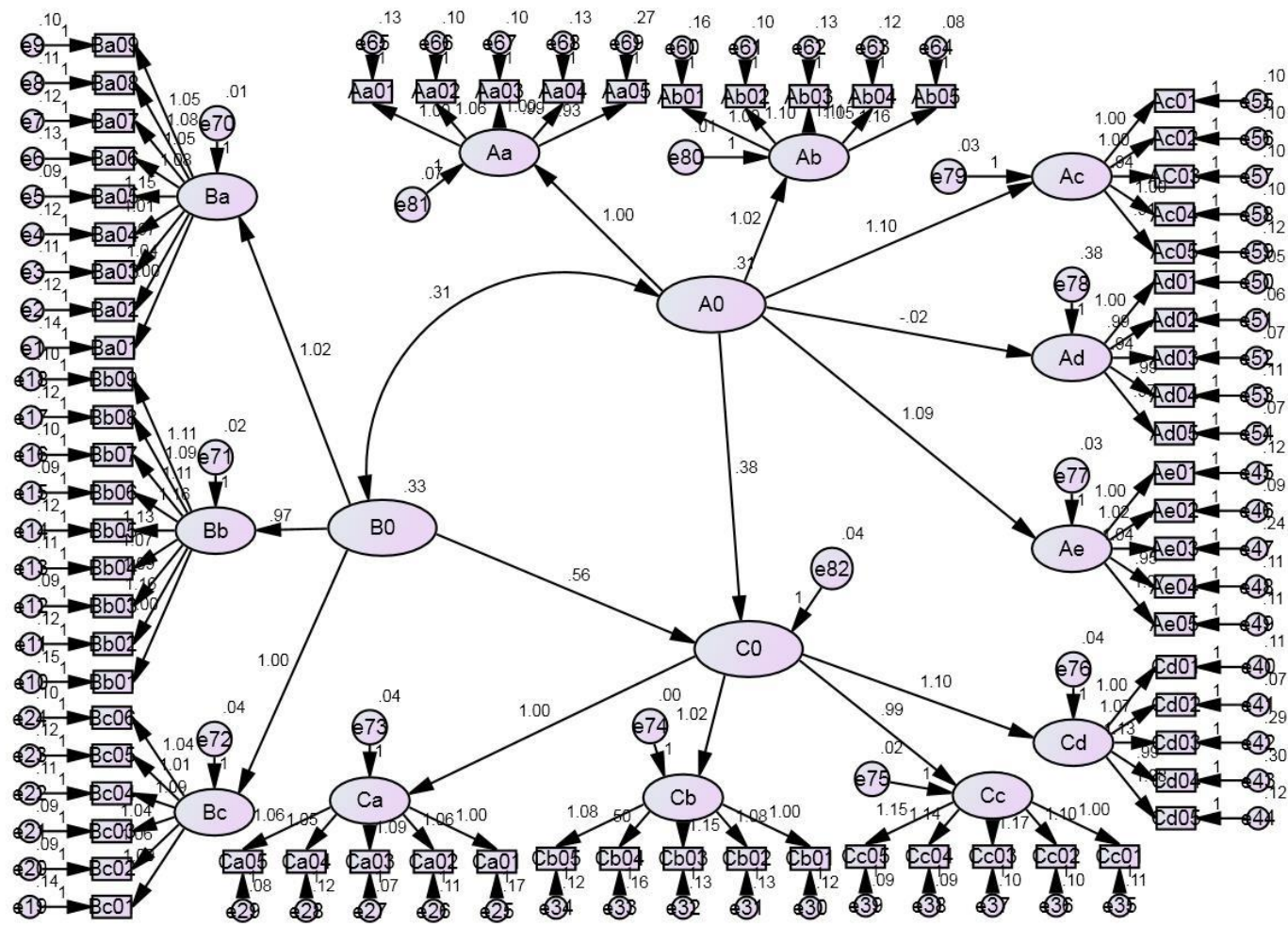

Figure 2. Statistical Model of Adult Career Planning Program Design, Program Contents, and Adaptive Assessment Learning Effectiveness.

In this study, there are no significant differences in the cognition and feelings of adults with different backgrounds regarding program design, program contents, or assessment adaptability. According to the calculation results, as shown in Table 5 and Figure 2, adult career planning program design and program contents have a path relationship with assessment adaptability. Adults are positively significantly related to program design and program contents; adults have significant predictive power of assessment adaptability of program design; adults have significant predictive power of assessment adaptability of program contents. To sum up, the validation results of the hypotheses in this study are detailed, as follows:

H1: The hypothesis that adults with different backgrounds have significant differences in their cognition and feelings about program design, program contents, and assessment adaptability is partially supported.

$\mathrm{H} 2$ : The hypothesis that adults are significantly related to program design and program contents is supported.

H3: The hypothesis that adults have significant predictive power of the assessment adaptability of program design is supported.

H4: The hypothesis that adults have significant predictive power of the assessment adaptability of program contents is supported. 
Table 5. Summary of Empirical Results of Research Hypotheses.

\begin{tabular}{|c|c|c|c|c|c|c|c|}
\hline Hypothesis & \multicolumn{3}{|c|}{ Path Relationship } & $\begin{array}{c}\text { Path } \\
\text { Value }\end{array}$ & C.R. & $p$ & $\begin{array}{l}\text { Supported } \\
\text { Hypothesis }\end{array}$ \\
\hline 2 & Program design & $<-->$ & $\begin{array}{l}\text { Program } \\
\text { contents }\end{array}$ & .31 & $10.22 *$ & $* * *$ & Supported \\
\hline 3 & $\begin{array}{c}\text { Learning } \\
\text { effectiveness }\end{array}$ & $<--->$ & $\begin{array}{c}\text { Program } \\
\text { design }\end{array}$ & .38 & $2.96^{*}$ & $* * *$ & Supported \\
\hline 4 & $\begin{array}{c}\text { Learning } \\
\text { effectiveness }\end{array}$ & $->$ & $\begin{array}{l}\text { Program } \\
\text { contents }\end{array}$ & .56 & $4.40^{*}$ & $* * *$ & Supported \\
\hline
\end{tabular}

$* \mathrm{P}<.05 * * * \mathrm{P}<.001$

\section{Conclusion and suggestions}

Global, diversified, and uncertain workplace environments of the economic industry causes adults, in the face of career planning, to evolve from the "linear trend" to the "nonlinear and changeable trend", in an effort to develop proper career development goals and re-establish their goals at any time, and then, learn and sharpen their skills, in order that they do not become obsolete in the workplace. In addition, as science and technology are constantly developing, adult learners must re-adjust their career planning, as well as the items and connotations of professional and core competency, and learn new knowledge and new technology, especially as human resources may deviate from the trend of Industry 4.0. Under the impacts and challenges of workplace environment, if adults fail to actively identify the functions and positioning of human resources in the global industrial chain, it is difficult for them to persistently develop their career and competency.

Therefore, this study proposes the following adult learner attributes as the foundation for career planning and competency development program design: develop design architectures of program learning concepts for adult learners' career planning and competency development, and formulate a performance-oriented diversified result assessment system and other feasible strategies for performance-oriented training for career planning and career development. These items can provide recommendations and references for adult education institutions regarding adult learner professional career and competency development programs, as well as teaching activity designs, and assist adult learners to construct adaptive program learning maps, which include cross-domain, integrated, contingent, and appropriate career planning and development competency items. Consequently, when confronted with the current paradoxical world context, adults should take a positive attitude, keep up with the times, and continuously hone their skills, in order master the best career development opportunities.

\section{References}

1. I.C. Kao, Journal of Agriculture and Leisure Industry Research, 7(1), 17-38 (2017)

2. S.J. Wang, Globalization and Adult Education, 99-122 (2002)

3. I.C. Kao, Empirical Study on the Learning Purposes, Contents, and Methods for Adults in Response to Globalization. Storage Management Solutions, 1, 199-220 (2016)

4. I.C. Kao, Academy of Education Institute, 1, 2-10 (2003)

5. I.C. Kao, Journal of Urbanology, 1(1), 85-113 (2010)

6. F.S. Huang, Introduction to Adult Education (Wu Nan Books, Taipei, 2000)

7. Adult Education Institute of Republic of China, Globalization and Adult Education(ShiTa Books, Taipei, 2014)

8. P.C. Tsai and W.Y. Wu, Adult Education (Li Wen Publishing, Kaohsiung, 2010)

9. D.M. Randall, Academy of Management Review, 12(3), 462 (1987)

10. T.H. Yeh, Research into the Impact of Workplace Changes on Adult Career Planning(master's thesis), Graduate Institute of Guidance and Counseling of National Chi Nan University (to be published) 
11. H.L. Peng, M.H. Chiang and Y.S. Lin(trans), Adult Career Development - Concepts, Topics and Practices (Original author: Spencer G. Niles) (Psychological Publishing, Taipei, 2009)

12. P. Herriot and C. Pemberton, Human Resources Management Journal, 7(1), 45-56 (1997)

13. N. Nicholson, Academy of Management Review, 23(1), 40-51 (1996)

14. R. Driver, A. Squires, P. Rushworth and V. Wood-Robinson, Making Sense of Secondary Science (Routledge, London, 1994)

15. D.K. Duys, J.E. Ward, J.A. Maxwell and L.E. Comerford, The Career Development Quarterly, 56, 232-241 (2008)

16. C.L. Kang, Employment and Training, 15(6), 3-9 (1997)

17. S.C. Wu, Psychological Testing, 60(2), 397-428 (2013)

18. C.J. Chiu, T\&D FASHION, 202, 1-32 (2015)

19. W.C. Liao, Competency Implementation and Packaged Training, 2010 Taiwan Labor Forum(Taipei, Taiwan, 2010)

20. P.W. Huang, Competency Analysis and Development. Published in Affiliated Vocational Training Center of DerJian Enterprises Ltd., Alltalent Education Development Co., Ltd. (ed.), Training Manager Level 5 Certification Course Materials (39-139) (Tainan, Taiwan, 2014)

21. M.A. Campion, A.A. Fink, B.J. Ruggeberg, L. Carr, G.M. Phillips and R.B. Odman, Personnel Psychology, 64, 225-262 (2011)

22. L.M. Spencer and S.M. Spencer, Competence at work: Models for superior performance (New York, USA, 1993)

23. P.J. Guglielmino, Training \& Development Journal, 33(4), 12-14 (1979)

24. R.L. Katz, Harvard Business Review, 33(1), 33-42 (1955)

25. M.J. Huang and Y.C. Cheng, The Journal of Guidance \& Counseling, 30(1), 61-87 (2008)

26. Y.S. Lan, Bottleneck and breakthrough in the Use of Competency (1), November 18, 2014, from SUNNET: http://www.sun.net.tw/knowledge/knowledge.php?type= 0 (2009)

27. J.J. Li and J.C. Cheng, Construction of Management Competency Model, W.C. Lin(Host), Management Competency Development, 14th Presentation of Special Research Results into Enterprise Human Resource Management Practices, National Central University (2008)

28. G.H. Deng, Establishment of Evaluation Table of Executives' Management Ability and Validity Analysis - A Case Study of a Commercial Bank(master's thesis), Institute of Human Resource Management of National Central University (to be published)

29. Workforce Development Agency, "Occupation" and "Class", December 15, 2015, from the website of iCAP Competency Development Platform: https://icap.wda.gov.tw/Knowledge/knowledge_introduction.aspx (2015)

30. J.C. Kuo, Employment Security, 9 (1), 60-66 (2010)

31. C. Hodell, Basics of Instructional Systems Developmen(ATD, USA, 2005)

32. W.T. Lin, C.Y. Kung and L.L. Lin, Analysis of Differences in IIP, ISO 10015 and TTQS, Quality Journal, 45(4), 52-56 (2009)

33. C.S. Lin, Human Capital Development and National Training Quality Assurance System Employment Security, 5(2), 44-51 (2006)

34. Workforce Development Agency, TTQS Evaluation Indicators. November 12, 2014, from the website of TTQS: http://ttqs.wda.gov.tw/ (2014)

35. J.C. Liao, Discussion on Improving Education, Training and Human Resource Quality from International Standards ISO 10015 and IIP, Quality Journal, 40(10), 28-31 (2004)

36. I.C. Kao, Construction of Human Resource Development Strategy of Community Empowerment by Project Management, TOC and TTQS, Storage Management Solutions, 2, 42-65 (2014)

37. J.C. Chang, "Technical and Vocational Education" in Response to Industry 4.0, May 18, 2017, from the website of Craftsmanship Insights: http://www.tvet3.info/vocational-education-4-0 (2017)

38. J. Dalziel, et al., Journal of Interactive Media in Education, 2016(1):7, 1-24 (2016) 
39. Workforce Development Agency, TTQS Uniform Textbooks for Indicator Programs for Enterprises and Institutions, November 12, 2014, from the website of TTQS, http://ttqs.wda.gov.tw/ (2014)

40. S.C. Cheng, P.C. Lin and Y.C. Cheng, Psychological Testing, 56(3), 397-430 (2009)

41. D.C. McClelland, American Psychologist, 28(1), 1-24 (1973)

42. T.L. Chen, T\&D Fashion, 161, 1-21(2013)

43. P.C. Tsai, Y.H. Hsu, Construction of Adult Learning System in the Trend of Globalization. Chinese Community Education Association (Chief Editor), Globalization and Adult Education, 331-355 (Normal University Press, Taipei, 2004)

44. M.L. Wu, Structural equation modeling: Operation and application of AMOS (Wu Nan Books, Taipei, 2007)

45. M.L. Wu and C.T. Tu, SPSS \& the Application and Analysis of Statistics (Wu Nan Books, Taipei, 2005)

46. M.C. Hsu, Journal of Sport and Recreation Management, 7(1), 174-18 (2010)

47. M.C. Hsu, F.C. Fan and C.M. Huang, Journal of Taiwan Society for Sport Management, 11(2), 85-107 (2011)

48. M.C. Hsu and H.P. Yen, International Journal of LISREL, 6(1), 24-56 (2013)

49. W.H. Chang, Techniques of thesis writing (Tingmao, Taipei, 2011)

50. S.Y. Chen, M.C. Hsu and F.E. Li, Journal of Leisure and Recreation Industry Management, 5(3), $1-21(2012)$

51. K.Y. Chen and C.H. Wang, Thesis statistical analysis practice SPSS and operation of AMOS (Wu Nan Books, Taipei, 2011)

52. C. Fornell and D.F. Lacker, Journal of Marketing Research, 18, 39-50 (1981)

53. J.F.Jr. Hair, R.E. Anderson, R.L. Tatham and W.C. Black, Multivariate data analysis (7th ed.) (Prentice Hall, New Jersey, 2009)

54. R.B. Kline, Principles and practice of structural equation modeling (2nd ed.) (Guilford Press, New York, 2005)

55. B. Thomopson, Exploratory and confirmatory factor analysis: Understanding concepts and applications (American Psychological Association, Washington DC, 2004)

56. R.P. Bagozzi and Y.Yi, Journal of the Academy of Marketing Science, 16, 74-94 (1988)

57. J.F.Jr. Hair, R.E. Anderson, R.L. Tatham and W.C. Black, Multivariate data analysis (5th ed.) (Prentice Hall, New Jersey, 1998)

58. G. Torkzadeh, X. Koufteros and K. Pflughoeft, Structural Equation Modeling, 10(2), 263-275 (2003) 